\title{
Thermal performance of biosourced materials on Buildings: The case of Typha Australis
}

\author{
Labouda Ba ${ }^{1,2,3}$, Ikram El Abbassi ${ }^{2}$, Cheikh S.E Kane ${ }^{3}$, A-M Darcherif ${ }^{1}$, Mamoudou Ndongo $^{3}$ \\ ${ }^{1}$ Laboratoire de Quartz, Université de Cergy-Pontoise. \\ ${ }^{2}$ Laboratoire de Recherche en Eco-innovation Industrielle et Energétique (LR2E), ECAM-EPMI. \\ ${ }^{3}$ Unité de recherche appliquée sur les énergies renouvelables, Université de Nouakchott Al Asriya.
}

\begin{abstract}
Developing countries are facing population growth, which leads, on the one hand, to increased requirements for buildings and, on the other hand, to the depletion of fossil fuels along with exposure, of people living in those areas, to some detrimental consequences of climate change. Because of these factors, we propose approaches to control energy consumption in buildings. In some countries, the architectures adopted are not adequate to the environment and climate, resulting in discomfort in those buildings, in such circumstances, residents resort to the use of energy systems, such as heating, ventilation, and air conditioning, which leads to exorbitant electricity bills. Housing consumes $40 \%$ of the world's energy and is responsible for a third of greenhouse gas emissions. Optimizing energy needs in buildings is a solution to overcome these problems. For this purpose, there are solutions such as: the design of the building characterized by its shape and envelope, while using less energy-consuming equipment. For several years, the building materials sector has been developing with a particular focus on bio-source materials, which are generally materials with good thermal performance. In order to highlight the thermal performance of bio-source materials, we will study the case of Typha Australis which is a plant of the Typhaceae family that grows abundantly in an aquatic environment mainly in the Senegal River valley.Recent studies showed that Typha Australis has good thermal insulation properties. In order to determine the impact of Typha Australis on a building, a dynamic thermal simulation was carried out using the Trnsys software according to specific scenarios, the Typha was mixed with other local materials and used as a wall insulation panel, the result of the study shows that this fiber has allowed us to optimize energy consumption in a building. Mixing Typha with other materials (e. g. clay) is a promising solution for energy efficiency in buildings.
\end{abstract}

\footnotetext{
Corresponding author: nass.sahraoui@outlook.fr
} 


\section{Introduction}

Developing countries are facing an exponentially increasing rate of urbanization, hence the need for the development of social and decent housing. Given certain problems such as the emission of greenhouse gases and the depletion of fossil resources, it will be important to reduce the development of energy-intensive. Housing alone consumes $40 \%$ of the world's energy [1-2]. The implementation of social and less energy-intensive housing can be achieved through the design of a sustainable and bioclimatic housing.

This is done through the thermal inertia of the housing, thermal insulation, architecture, sobriety (use of less energy-intensive household appliances) [3]. Thermal insulation is a concept that is increasingly developing and can be made either by phase change materials or bio sourced materials.

Several African countries have a particular interest in bio sourced materials, thanks to their availability and they have proven to have good thermal performance [4-5].

The physical-thermal characterization of several biosourced materials gives a low thermal conductivity. These include the incorporation of peanut shells into the plaster in different percentages that have reduced the thermal conductivity of the composite [6]. The mixing of straw and weeds to make high-strength clay bricks increases the durability of the materials and gives good thermal performance [7]. Our study will focus on the exploitation of this plant as bio-sourced and isolation materials. A characterization study of this material has been done by some researchers [8-9].

Our simulation has been done with Trnsys, a dynamic thermal simulation software that has been used by several researchers around the world to evaluate the thermal effects of buildings [10].

Our main objective is to determine the thermal performance of a composite which is the mixture of clay, a local material with Typha which is a biosourced material, taking concrete as a reference habitat.

The next section of this paper presents our analysis and modelling approach, then we introduce our findings in the section results and discussion. We end this paper with some conclusions.

\section{Analysis and Modelling}

Two buildings were chosen and they are offices located in Nouakchott (Mauritania). The buildings are $4 \mathrm{~m}$-high with a double glazed window and a wooden door, the dimensions of the two buildings are identical as well as their doors and windows. The dimensions are shown in Table 1 .

The two buildings chosen differ in the composition of their walls and roofs. The first building is in breeze block and the second in clay, this clay is mixed with typha (22.9\% typha).

We study two scenarios and each scenario corresponds to a building type: scenario 1 to the breeze block building which is a classical building (reference building) and scenario 2 to the clay building. The simulation of these two buildings was carried out on Trnsys over one year (8760h) with a 1-hour step.

Tables 2 and 3 show the composition of the walls and roof for the scenario 1 (breeze block habitat) and Table 4 and 5 for the scenario 2 (clay habitat).

Table 1. Size of habitat

\begin{tabular}{|c|c|c|}
\hline & Length & width \\
\hline Walls and roofs & 15 & 0.95 \\
\hline Door & 2 & 1.5 \\
\hline Window & 1 & 1.38 \\
\hline
\end{tabular}

For scenario 1 :

Table 2. Composition of walls for scenario 1

\begin{tabular}{|c|c|c|}
\hline Composition & $\begin{array}{c}\text { Thickness } \\
(\mathrm{cm})\end{array}$ & $\begin{array}{c}\text { Thermal } \\
\text { conductivity } \\
(\mathrm{W} / \mathrm{mk})\end{array}$ \\
\hline Breeze block & 15 & 0.95 \\
\hline Cement mortar & 2 & 1.5 \\
\hline Plaster & 1 & 1.38 \\
\hline
\end{tabular}

Table 3. Composition of roof for scenario 1

\begin{tabular}{|c|c|c|}
\hline Composition & $\begin{array}{c}\text { Thickness } \\
(\mathrm{cm})\end{array}$ & $\begin{array}{c}\text { Thermal } \\
\text { conductivity } \\
(\mathrm{W} / \mathrm{mk})\end{array}$ \\
\hline Breeze block & 15 & 0.95 \\
\hline Cement mortar & 2 & 1.5 \\
\hline Plaster & 1 & 1.38 \\
\hline
\end{tabular}

For scenario 2:

Table 4. Composition of walls for scenario 2

\begin{tabular}{|c|c|c|}
\hline Composition & $\begin{array}{c}\text { Thinckness } \\
(\mathrm{cm})\end{array}$ & $\begin{array}{c}\text { Thermal } \\
\text { conductivity } \\
(\mathrm{W} / \mathrm{mk})\end{array}$ \\
\hline Clay+ Typha & 17 & 0.46 \\
\hline Plaster & 1 & 1.38 \\
\hline
\end{tabular}

Table 5. Composition of roof for scenario 2

\begin{tabular}{|c|c|c|}
\hline Composition & $\begin{array}{c}\text { Thinckness } \\
(\mathrm{cm})\end{array}$ & $\begin{array}{c}\text { Thermal } \\
\text { conductivity } \\
(\mathrm{W} / \mathrm{mk})\end{array}$ \\
\hline Clay+ Typha & 17 & 0.46 \\
\hline Plaster & 3 & 1.38 \\
\hline
\end{tabular}

the utilization of both buildings are identical for both building scenarios (breeze block and mixed clay and typha), Table 6 presents the use case. 
Table 6. Use scenario

\begin{tabular}{|c|c|c|c|}
\hline $\begin{array}{c}\text { Internal } \\
\text { charge }\end{array}$ & Numbers & $\begin{array}{c}\text { sensitive } \\
\text { powers }\end{array}$ & The duration \\
\hline Persons & 3 & $75 \mathrm{~W}$ & $\begin{array}{c}8 \mathrm{~h} \text { to } 18 \mathrm{~h} \\
\text { (Monday to } \\
\text { Friday) }\end{array}$ \\
\hline $\begin{array}{c}\text { devices } \\
\text { (computer) }\end{array}$ & 3 & $230 \mathrm{~W}$ & $\begin{array}{c}8 \mathrm{~h} \text { to } 18 \mathrm{~h} \\
\text { (Monday to } \\
\text { Friday) }\end{array}$ \\
\hline Light & 1 & $10 \mathrm{~W} / \mathrm{m} 2$ & $\begin{array}{c}8 \mathrm{~h} \text { to } 18 \mathrm{~h} \\
\text { (Monday to } \\
\text { Friday) }\end{array}$ \\
\hline
\end{tabular}

the ventilation used is natural ventilation with a rate of $2 \mathrm{~h} / \mathrm{m} 3$ and the set point temperature has been fixed at $22^{\circ} \mathrm{C}$. The energy system is put into operation during office occupancy (see Table 6).

\section{Results and Discussion}

The outdoor temperature of the site is presented in Figure 1 in order to give an idea of the climatic conditions of the site. We can see in Figure 1 that the temperature varies between 13 and $40^{\circ} \mathrm{C}$, which means that we do not need heating as an energy system. We will therefore study the impact of the use of the mixture of Typha and clay on the energy needs for air conditioning.

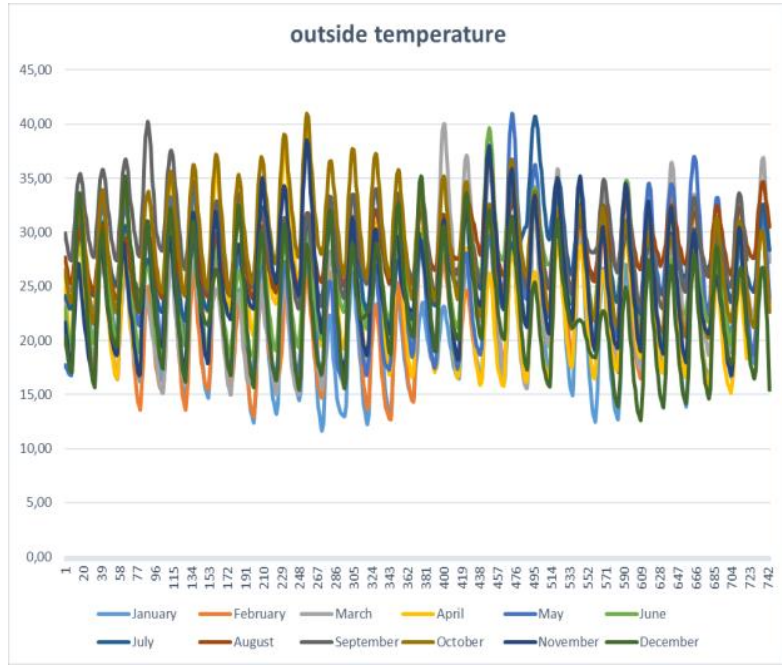

Fig.1.Variation in outside temperature for each month

Figures 2 and 3 show the change in the building's Air temperature (TAIR) and operative temperature (TOP) respectively after setting a set point temperature.

By definition, the operating temperature is the average between the average radiant temperature and the air temperature.

The air temperature inside the house is slightly lower than the outside temperature when it is less than or equal to 22 or when the building is unoccupied, these cases correspond to the non-use of energy systems, particularly air conditioning.

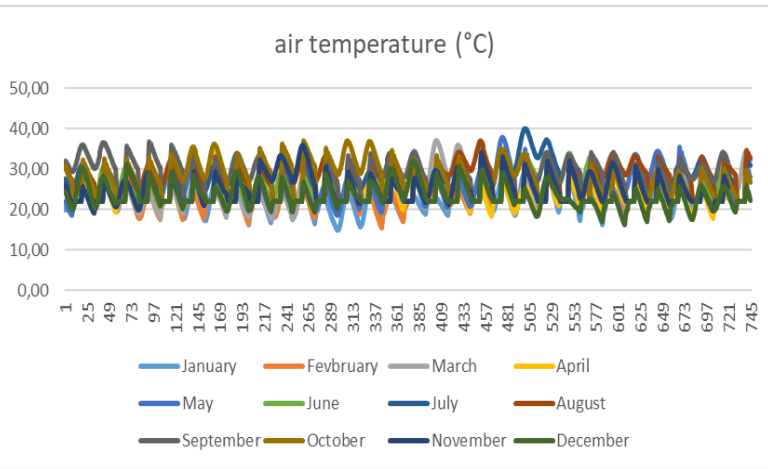

Fig.2.Air temperature inside the habitat

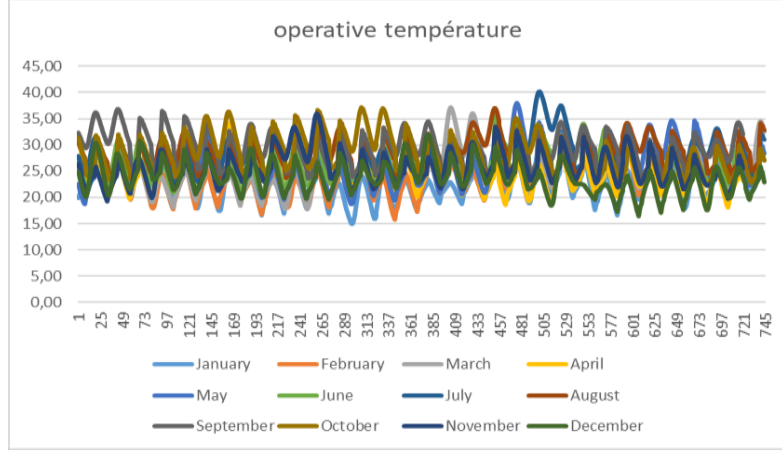

Fig.3.Operative temperature inside the habitat

Figure 4 shows the variations in air conditioning requirements according to the scenarios. By comparing the two buildings, we can see in Figure 4 that during the summer we have a large difference in energy demand, but a small difference in winter (December, January, February). This could be due to the low use of energy systems during this period.

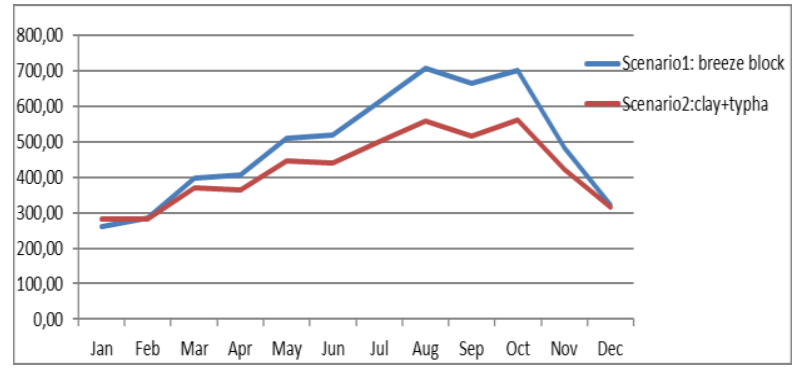

Fig.4.Air conditioning energy requirement (kwh)

By replacing Scenario 1 (breeze blocks) with Scenario 2 (in a mixture of clay and typha), the energy requirements for air conditioning decrease, which is explained by the thermal conductivity of the wall and roof compositions in Scenario 2, which is relatively lower than that in Scenario 1. Table 7 shows that the mixture of clay and 
typha has reduced the energy requirements for air conditioning by $14 \%$.

Table 7. Reduction rate

\begin{tabular}{|c|c|c|}
\hline Scenarios & $\begin{array}{c}\text { Energy } \\
\text { requirement } \\
(\mathrm{kwh})\end{array}$ & Reduction rate \\
\hline $\begin{array}{c}\text { Scenario 1 (breeze } \\
\text { block habitat) }\end{array}$ & 5878,10 & $0 \%$ ( reference) \\
\hline $\begin{array}{c}\text { Scenario 2 (clay } \\
\text { habitat) }\end{array}$ & 5067,567 & $14 \%$ \\
\hline
\end{tabular}

\section{Conclusion}

In this article, two buildings of different compositions were studied, the first in breeze block, which is the reference building, and the second in clay and typha mixture. Then a simulation on Trnsys was carried out to evaluate the thermal performance of these two buildings, in particular the impact of the use of typha and clay mixture. This study showed the interest of using biosourced materials, in particular typha, because its mixture with clay has reduced energy requirements by $14 \%$, which proves that the mixture of a local material and a biosourced material, in our case clay and typha, is a supporting composite for construction due to their thermal performance.

\section{References}

1. UN-Habitat, world Habitat day 2014 -voice from shms background paper, [online] Available http://unhabitat.org/wpcontent/uploads/2014/07/WH D-2014-Background-Paper.pdf.

2. S.Mandelli,2014, Renewable and Sustainable Energy, 37, 656 .

3. S.M.A. Bekkouche, 2011, Energy and Buildings, 43, 2414.

4. M.Kabore, 2014, PhD. Thesis .2IE, Université de Grenoble Alpes, Génie Civil et Science de l'habitat, LISTIC-EA3703, LESEE, ED-SISEO, ED-2IE, P24.

5. N. Aste, 2017, Sustainable Building Design in Kenya Energy Procedia, 105, 2803.

6. M.Lamrani 2017, case studies in construction materials, 7, 294

7. X.Zhang, 2015, Procedia Engineering,121, 2044 2051

8. Y.Dieye, V. M., 2017, Journal of Building Engineering, 9, 142.

9. M.T.DiATTA, S. A, 2011, Cong. SFT, Perpignan.

10. S. Klein,2000, A University of Wisconsin-Madison, Madison,WI, USA. 